\title{
Functionalized organic frameworks explored as second order NLO agents
}

\author{
ANIL K SINGH $^{\mathrm{a}}$, BRIJESH RATHI ${ }^{\mathrm{b}}$,* VOLODYMYR V MEDVIEDIEV ${ }^{\mathrm{c}}$, OLEG V SHISHKIN $^{\mathrm{c}}$, \\ VIJAY BAHADUR ${ }^{\mathrm{a}}$, TARUNA SINGH ${ }^{\mathrm{b}}$, BRAJENDRA K SINGH ${ }^{\mathrm{a}}$, N VIJAYAN ${ }^{\mathrm{d}}$, \\ V BALACHANDRAN ${ }^{\mathrm{e}}$ and NIKOLAY YU GOROBETS ${ }^{\mathrm{c}}$ \\ ${ }^{a}$ Bio-organic Research Laboratory, Department of Chemistry, University of Delhi, Delhi 110 007, India \\ ${ }^{b}$ Department of Chemistry, Hansraj College, University of Delhi, Delhi 110007 India \\ "State Scientific Institution "Institute for Single Crystals", National Academy of Science of Ukraine, \\ 60 Leninaave, Kharkiv 61001, Ukraine \\ ${ }^{\mathrm{d}}$ CSIR-National Physical Laboratory, Dr. K S Krishnan Road, New Delhi 110 012, India \\ ePG\& Research Department of Physics, Arignar Anna Government Arts College, Musiri 621 211, India \\ e-mail: brijeshrathi@hrc.du.ac.in
}

MS received 17 September 2015; revised 17 November 2015; accepted 18 November 2015

\begin{abstract}
A new class of chiral phthalimides functionalized with aryl piperazines was designed anticipating their strong candidature for crystal engineering and technological applications. Five new phthalimides were synthesized, characterized and subjected to single crystal X-ray diffraction study that directed their noncentrosymmetric structures. Four phthalimides crystallized in $P 2_{1}$ space group with monoclinic crystal system, however, one was found to possess $P 22_{1} 2_{1} 2_{1}$ space group with orthorhombic system. The supramolecular architectures of phthalimide crystals were analysed by an approach based on consideration of energy of intermolecular interaction. The molecular hyperpolarizability $(\beta)$ calculation for all the listed phthalimides indicated their promising candidature for NLO materials. Further, the crystalline form of all phthalimides was evaluated for their second harmonic generation (SHG) response. A significant response of $16.4 \mathrm{mV}$ was measured for phthalimide possessing $t$-butyl substituent at the para position of 4-benzylpiperazine. This high SHG response may be attributed to the molecular chirality and helical supramolecular frameworks stabilized by $\mathrm{C}-\mathrm{H} \cdots \mathrm{O}$ hydrogen bonds in the solid state. The current study attests chiral phthalimides possessing arylpiperazines as effective nominees to the area of crystal engineering and nonlinear optics.
\end{abstract}

Keywords. Arylpiperazine; crystal engineering; hyperpolarizability; phthalimide; SHG response.

\section{Introduction}

The area of nonlinear optics has attracted enough attention in the past three decades not only due to the numerous applications in optical modulation, second-harmonic generation, optical signal processing, optical switching, optical data storage devices, etc., but also owing to the fundamental research connected to the issues like charge transfer, conjugation, polarization and crystallization into non-centrosymmetric lattices. ${ }^{1-4}$ A variety of systems including inorganic materials, organometallic materials, organic molecules and polymers have been studied for nonlinear optical (NLO) activity. ${ }^{5}$ Among all these, neutral organic molecules are of much interest due to their chemical tunability and choice of synthetic strategies. Besides, organic molecules are comparatively less explored in terms of their technological applications. A number of organic $\pi$-conjugated molecules have been investigated with their function

\footnotetext{
*For correspondence
}

suitability as components in the hypothetical NLO materials. ${ }^{4,6}$ The flexibility associated with the structural modifications of organic molecules offers the possibility to fabricate tailor-made molecules and to fine-tune their properties for the desired applications. In addition, large optical susceptibilities, inherent ultrafast response times, and high optical thresholds of organic molecules make them a great deal of attraction over pure inorganic materials. ${ }^{2,7}$ Nonlinear optical efficacy of the organic materials is governed by their non-centrosymmetric structures, great hyperpolarizability $(\beta)$ and their packing motifs in the solid state. ${ }^{8}$ Organic molecules with long conjugation systems that usually exhibit high $\beta$ values are certainly strong candidates in the area of non-linear optics. Regrettably, only a few organic molecules with high $\beta$ values crystallized in non-centrosymmetric style, and even fewer of them are useful for NLO materials. ${ }^{9}$ A number of methodologies have been employed to overcome this problem, viz., choosing pure enantiomers ${ }^{10}$ using inclusion complexes. One of the methods to achieve 
non-centrosymmetry is to imply the chirality in the molecules. Such molecules are definitely non-centrosymmetric, and their second-order NLO response is therefore nonzero. ${ }^{11}$ To date, the organic NLO materials are yet to find practical applications, ${ }^{12}$ however, inorganic materials such as lithium niobate and potassium dihydrogen phosphate (KDP) are exclusively used in electrooptic devices. ${ }^{13}$ Despite the tremendous progress in this area, rational design and synthesis of organic NLO crystals with non-centrosymmetric structures possessing high temporal and thermal stabilities remains a challenge. The presence of one or more chiral centres in a molecule helps to achieve non-centrosymmetric structure and this strategy has been employed to obtain new non-centrosymmetric materials. ${ }^{14}$ Recently, we have explored the structural features and NLO properties of chiral phthalimides (I-III). ${ }^{15}$ Phthalimides (I-III) shown in chart 1 were established as robust and encouraging synthons for the formation of supramolecular frameworks stabilized by $\mathrm{C}-\mathrm{H} \cdots \mathrm{O}$ hydrogen bonding which reveals their significance in crystal engineering. ${ }^{16}$ Phthalimide scaffold possesses a bit of peptide like character and shows $\pi$-acceptor site and also can take part in the formation of hydrogen bonds. ${ }^{17,18}$ The dipolar arrangements and aromatic nature of phthalimide structural motifs along with hydrogen bonding are the basis of supramolecular architectures. ${ }^{18}$ The chirality is the only factor that guarantees a non-centrosymmetric lattice for symmetry reasons. ${ }^{14}$ The chiral amino acid fragments were introduced in order to generate the chirality in phthalimides. ${ }^{19}$

Herein, we present five novel chiral phthalimides (3a-3e) as an asset for the class of non-centrosymmetric organic materials possessing significant SHG Efficiency. The supramolecular architectures of phthalimides are investigated by an approach based on consideration of the energy of intermolecular interactions. This method allows the recognition of strongly bonded fragments of crystals which may be considered as basic structural motif (BSM).

\section{Experimental}

\subsection{General synthetic procedure for compounds (3a-e)}

To the solution of $N$-phthaloyl-L-amino acid $(0.4 \mathrm{mmol})$ in dichloromethane $(20 \mathrm{~mL}), \mathrm{N}$-(3-Dimethylaminopropyl)-N'-ethylcarbodiimide hydrochloride (EDC. $\mathrm{HCl})$ $(0.6 \mathrm{mmol})$ and triethylamine (TEA, $1.6 \mathrm{mmol})$ were added and the contents were stirred at $0^{\circ} \mathrm{C}$ for $15 \mathrm{~min}$ to secure homogeneous mixture. Subsequently, Hydroxybenzotriazole $(\mathrm{HOBt})(0.6 \mathrm{mmol})$ was added to the reaction mixture and stirred for another $15 \mathrm{~min}$ at $0^{\circ} \mathrm{C}$. $\mathrm{N}$-substituted piperazines $(0.48 \mathrm{mmol})$ were added and the reaction mixture was further stirred for $24 \mathrm{~h}$ at room temperature. The solvent was evaporated under reduced pressure and the reaction mixture was extracted with ethyl acetate and water. The organic layer was concentrated and purified by column chromatography (ethyl acetate/petroleum ether, 4:6).

\subsection{Spectral Data}

2.2a (S)-2-(1-(4-(4-bromobenzyl)piperazin-1-yl)-4-meth$y$ l-1-oxopentan-2-yl)isoindoline-1,3-dione $(\mathbf{3 a})$ : The title compound was obtained as a white solid. Yield: $82 \%$; $162 \mathrm{mg}$; M.p.: $149.11^{\circ} \mathrm{C} ;[\alpha]_{\mathrm{D}}^{25}:-14.34$ (c = 0.2 in Ethylacetate); FTIR (KBr) $v_{\max } / \mathrm{cm}^{-1}: 2956$, 2927, 1717 ( $\mathrm{C}=\mathrm{O}$, isoindoline), $1638(\mathrm{C}=\mathrm{O}$, amide), 1450, 1375, 1071, 722; ${ }^{1} \mathrm{H}$ NMR $\left(400 \mathrm{MHz}, \mathrm{CDCl}_{3}\right)$ : $\delta 7.82(\mathrm{~m}, 2 \mathrm{H}), 7.71(\mathrm{~m}, 2 \mathrm{H}), 7.40(\mathrm{~d}, J=8.05 \mathrm{~Hz}$, $2 \mathrm{H}), 7.15(\mathrm{~d}, J=8.05 \mathrm{~Hz}, 2 \mathrm{H}), 5.11(\mathrm{dd}, J=4.39$, $3.66 \mathrm{~Hz}, 1 \mathrm{H}), 3.63$ (br s, 2H), 3.50 (s, 2H), 3.46 (br $\mathrm{s}, 2 \mathrm{H}), 2.56(\mathrm{~m}, 1 \mathrm{H}), 2.47$ (br s, 4H), $1.64(\mathrm{~m}, 1 \mathrm{H})$, $1.55-1.47(\mathrm{~m}, 1 \mathrm{H}), 0.91(\mathrm{~d}, J=5.86 \mathrm{~Hz}, 6 \mathrm{H}) \mathrm{ppm} ;{ }^{13} \mathrm{C}$ NMR $\left(100 \mathrm{MHz}, \mathrm{CDCl}_{3}\right): \delta 168.1,167.8,134.9,134.1$, 131.6, 131.5, 131.0,123.4, 121.6, 61.6, 52.3, 49.9, 37.1, 25.1,23.0, $21.2 \mathrm{ppm}$, Elemental analysis calculated (\%) for $\mathrm{C}_{25} \mathrm{H}_{28} \mathrm{BrN}_{3} \mathrm{O}_{3}$ : C 60.24, $\mathrm{H}$ 5.66, $\mathrm{N}$ 8.43; found: C 59.92, H 5.46, N 8.06. HRMS $m / z$ calculated $[\mathrm{M}]^{+}$ for $\mathrm{C}_{25} \mathrm{H}_{28} \mathrm{BrN}_{3} \mathrm{O}_{3}^{+}$: 497.1314; found: 497.1292.

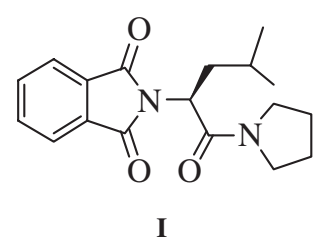

orthorhombic system $P 2{ }_{1} 2_{1} 2_{1}$ SHG $8.8 \mathrm{mV}$

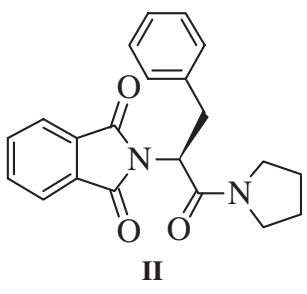

orthorhombic system $P 2{ }_{1} 2_{1} 2_{1}$ SHG $10.2 \mathrm{mV}$

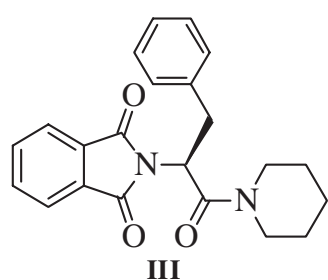

monoclinic system $P 2_{1}$

SHG $9.7 \mathrm{mV}$

Chart 1. Previously studied chiral phthalimides (I-III). 
$2.2 \mathrm{~b}$ (S)-2-(1-(4-(4-fluorobenzyl)piperazin-1-yl)-4-methyl-1-oxopentan-2-yl)isoindoline-1,3-dione (3b): The title compound was obtained as a white solid. Yield: 79\%; $140 \mathrm{mg}$; M.p.: $104.9^{\circ} \mathrm{C} ;[\alpha]_{\mathrm{D}}{ }^{29}:-7.81(\mathrm{c}=0.2$ in Ethylacetate); FTIR (KBr) $v_{\max } / \mathrm{cm}^{-1}: 2968,2928,1717$ $(\mathrm{C}=\mathrm{O}$, isoindoline $), 1638(\mathrm{C}=\mathrm{O}$, amide $), 1450,1385$, 1074, 722; ${ }^{1} \mathrm{H}$ NMR $\left(400 \mathrm{MHz}, \mathrm{CDCl}_{3}\right): \delta 7.84(\mathrm{~m}$, $2 \mathrm{H}), 7.73(\mathrm{~m}, 2 \mathrm{H}), 7.27(\mathrm{~d}, J=5.52 \mathrm{~Hz}, 2 \mathrm{H}), 7.15$ $(\mathrm{t}, J=8.70 \mathrm{~Hz}, 2 \mathrm{H}), 5.13(\mathrm{dd}, J=4.12,11.45 \mathrm{~Hz}$, 1H), 3.63 (br s, 2H), 3.47 (s, 4H), 2.61 (m, 1H), 2.42 (br s, 4H), $1.67(\mathrm{~m}, 1 \mathrm{H}), 1.54(\mathrm{~m}, 1 \mathrm{H}), 0.93(\mathrm{~d}, J=$ $3.17 \mathrm{~Hz}, 3 \mathrm{H}), 0.91(\mathrm{~d}, J=3.17 \mathrm{~Hz}, 3 \mathrm{H}) \mathrm{ppm} ;{ }^{13} \mathrm{C}$ NMR $\left(100 \mathrm{MHz}, \mathrm{CDCl}_{3}\right): \delta 168.1,167.7,134.1,131.6$, 130.6, 123.4, 115.2, 115.0, 61.7, 52.6, 52.3, 49.9, 37.1, 25.1, 23.0, $21.1 \mathrm{ppm}$; Elemental analysis calculated (\%) for $\mathrm{C}_{25} \mathrm{H}_{28} \mathrm{FN}_{3} \mathrm{O}_{3}$ : C 68.63, H 6.45, N 9.60; found: C 68.47, H 7.23, N 9.42. HRMS $m / z$ calculated $[\mathrm{M}]^{+}$ for $\mathrm{C}_{25} \mathrm{H}_{28} \mathrm{FN}_{3} \mathrm{O}_{3}{ }^{+}$: 437.2115; found: 437.2110.

\section{2c (S)-2-(4-methyl-1-oxo-1-(4-(4-(trifluoromethyl)} benzyl)piperazin-1-yl)pentan-2-yl)isoindoline-1,3-dione (3c): The title compound was obtained as a white solid. Yield: $81 \%$; $156 \mathrm{mg}$; M.p.: $140.6^{\circ} \mathrm{C} ;[\alpha]_{\mathrm{D}}{ }^{29}:-10.35$ (c $=0.2$ in Ethylacetate); FTIR (KBr) $v_{\max } / \mathrm{cm}^{-1}: 2941$, $1718(\mathrm{C}=\mathrm{O}$, isoindoline $), 1653(\mathrm{C}=\mathrm{O}$, amide $), 1444$, 1321, 1126, 721; ${ }^{1} \mathrm{H}$ NMR (400 MHz, $\left.\mathrm{CDCl}_{3}\right): \delta 7.78$ (m, 4H), $7.52(\mathrm{~m}, 4 \mathrm{H}), 5.06(\mathrm{~d}, J=9.52 \mathrm{~Hz}, 1 \mathrm{H}), 3.54$ $(\mathrm{m}, 5 \mathrm{H}), 2.36(\mathrm{~m}, 4 \mathrm{H}), 1.58(\mathrm{~m}, 3 \mathrm{H}), 1.18(\mathrm{~m}, 1 \mathrm{H})$, $0.88(\mathrm{~d}, J=6.87 \mathrm{~Hz}, 3 \mathrm{H}) \mathrm{ppm} ;{ }^{13} \mathrm{C}$ NMR $(100 \mathrm{MHz}$, $\left.\mathrm{CDCl}_{3}\right): \delta 168.1,167.7,134.1,131.6,129.4,125.3$, 123.4, 61.9, 52.8, 49.9, 37.2, 25.2, 23.0, 21.2, ppm; Elemental analysis calculated $(\%)$ for $\mathrm{C}_{26} \mathrm{H}_{28} \mathrm{~F}_{3} \mathrm{~N}_{3} \mathrm{O}_{3}$ : C 64.06, H 5.79, N 8.62; found: C 64.16, H 5.62, N 8.71. HRMS $m / z$ calculated $[\mathrm{M}]^{+}$for $\mathrm{C}_{26} \mathrm{H}_{28} \mathrm{~F}_{3} \mathrm{~N}_{3} \mathrm{O}_{3}^{+}$: 487.2083; found: 487.2032 .

2.2d (S)-2-(1-(4-(4-(tert-butyl)benzyl)piperazin-1-yl)4-methyl-1-oxopentan-2-yl)isoindoline-1,3-dione (3d): The title compound was obtained as a white solid. Yield: $75 \%$; $141 \mathrm{mg}$; M.p.: $139.2^{\circ} \mathrm{C}$ (DSC); $[\alpha]_{\mathrm{D}}{ }^{29}:-12.38$ (c $=0.2$ in Ethylacetate); FTIR $(\mathrm{KBr}) v_{\max } / \mathrm{cm}^{-1}: 3007$, 2960, 2870, $1715(\mathrm{C}=\mathrm{O}$, isoindoline $), 1656(\mathrm{C}=\mathrm{O}$, amide), 1440, 1373, 1262, 721; ${ }^{1} \mathrm{H}$ NMR (400 MHz, $\left.\mathrm{CDCl}_{3}\right): \delta 7.83(\mathrm{~m}, 2 \mathrm{H}), 7.71(\mathrm{~m}, 2 \mathrm{H}), 7.32(\mathrm{~d}, J=$ $8.05 \mathrm{~Hz}, 2 \mathrm{H}), 7.23(\mathrm{~d}, J=7.32 \mathrm{~Hz}, 2 \mathrm{H}), 5.11\left(\mathrm{dd},{ }^{3} J\right.$ $=10.98,3.66 \mathrm{~Hz}, 1 \mathrm{H}), 3.65(\mathrm{br} \mathrm{s}, 2 \mathrm{H}), 3.48(\mathrm{~s}, 4 \mathrm{H})$, $2.62(\mathrm{~m}, 1 \mathrm{H}), 2.44$ (br s, 4H), $1.69(\mathrm{~m}, 1 \mathrm{H}), 1.57(\mathrm{~m}$, 1H), 1.32 (s, 9H), 0.96 (d, $J=0.92 \mathrm{~Hz}, 3 \mathrm{H}), 0.94$ (d, $J$ $=1.37 \mathrm{~Hz}, 3 \mathrm{H}), \mathrm{ppm} ;{ }^{13} \mathrm{C} \mathrm{NMR}\left(100 \mathrm{MHz}, \mathrm{CDCl}_{3}\right): \delta$ 168.1, 167.6, 150.2, 134.0, 131.6, 128.7, 125.1, 123.3, $62.3,52.8,52.6,49.9,45.4,42.3,37.1,34.4,31.3$, 25.1, 23.0, $21.1 \mathrm{ppm}$; Elemental analysis calculated
(\%) for $\mathrm{C}_{29} \mathrm{H}_{37} \mathrm{~N}_{3} \mathrm{O}_{3} \mathrm{C} 73.23, \mathrm{H} 7.84, \mathrm{~N}$ 8.83; found: $\mathrm{C}$ 73.22, $\mathrm{H}$ 7.62, N 8.72. HRMS $m / z$ calculated $[\mathrm{M}]^{+}$for $\mathrm{C}_{29} \mathrm{H}_{37} \mathrm{~N}_{3} \mathrm{O}_{3}^{+}$: 475.2835; found: 475.2824.

2.2e (S)-2-(1-(4-(4-fluorobenzyl)piperazin-1-yl)-3-methyl1-oxobutan-2-yl)isoindoline-1,3-dione (3e): The title compound was obtained as a white solid.Yield: $85 \%$; $145 \mathrm{mg}$; M.p.: $135.0^{\circ} \mathrm{C}(\mathrm{DSC}) ;[\alpha]_{\mathrm{D}}{ }^{27}:-74.6(\mathrm{c}=0.2$ in Ethylacetate); FTIR (KBr) $v_{\max } / \mathrm{cm}^{-1}: 2959,2809$, $1728(\mathrm{C}=\mathrm{O}$, isoindoline $), 1665(\mathrm{C}=\mathrm{O}$, amide $), 1587$, 1474, 1277, 1113, 728; ${ }^{1} \mathrm{H}$ NMR (400 MHz, $\mathrm{CDCl}_{3}$ ): $\delta 7.84(\mathrm{~m}, 2 \mathrm{H}), 7.74(\mathrm{~m}, 2 \mathrm{H}), 7.26(\mathrm{~d}, J=5.95 \mathrm{~Hz}$, 2H), $6.98(\mathrm{t}, J=8.24 \mathrm{~Hz}, 2 \mathrm{H}), 4.64(\mathrm{~d}, J=10.08 \mathrm{~Hz}$, $1 \mathrm{H}), 3.67(\mathrm{~m}, 4 \mathrm{H}), 3.43(\mathrm{~s}, 2 \mathrm{H}), 3.09(\mathrm{~m}, 1 \mathrm{H}), 2.38(\mathrm{~m}$, $4 \mathrm{H}), 1.04(\mathrm{~d}, J=6.41 \mathrm{~Hz}, 3 \mathrm{H}), 0.87(\mathrm{~d}, J=6.87 \mathrm{~Hz}$, $3 \mathrm{H}), \mathrm{ppm} ;{ }^{13} \mathrm{C} \mathrm{NMR}\left(100 \mathrm{MHz}, \mathrm{CDCl}_{3}\right): \delta 167.7$, $166.5,134.2,131.3,130.6,130.5,123.5,115.2,115.0$, 61.7, 56.1, 52.8, 52.5, 45.4, 42.1, 27.5, 20.5, $19.1 \mathrm{ppm}$; Elemental analysis calculated $(\%)$ for $\mathrm{C}_{24} \mathrm{H}_{26} \mathrm{FN}_{3} \mathrm{O}_{3}$ : C 68.07, H 6.19, N 9.92; found: C 68.27, H 6.12, N 10.01. HRMS $m / z$ calculated $[\mathrm{M}]^{+}$for $\mathrm{C}_{24} \mathrm{H}_{26} \mathrm{FN}_{3} \mathrm{O}_{3}^{+}$: 423.1958; found: 423.1970 .

\subsection{Crystallographic Details}

Crystals of compounds (3a-3e) were obtained by slow evaporation of solution of compound in ethylacetatehexane solutions. X-Ray diffraction experiments were performed using Oxford Xcalibur $\mathrm{S}$ diffractometer $(\mathrm{MoK} \alpha$ radiation, graphite monochromator, $\mathrm{CCD}$ detector). All structures were solved by direct methods using SHELXL 97 program package. Positions of the hydrogen atoms were located from difference maps of electron density and refined using riding model with $\mathrm{U}_{\text {iso }}=\mathrm{nU}_{\mathrm{eq}}$ of carrier non-hydrogen atom $(\mathrm{n}=1.5$ for methyl groups and 1.2 for other $\mathrm{H}$ atoms). Crystallographic data, parameters of data collection and structure refinement are listed in Table S1 (See Supporting Information). The analysis of supramolecular architecture of the crystals under consideration was performed using an energetic approach suggested earlier. ${ }^{20,21}$ First coordination sphere of each molecule located in the asymmetric part of unit cell was determined as it was suggested before using "Molecular Shell calculation" option of Mercury program (version 3.1). ${ }^{22}$ Energies of intermolecular interactions were calculated using Density Functional Theory with B3LYP functional ${ }^{23-27}$ augmented by the D3 empirical correction for dispersion interactions ${ }^{28}$ with def2-TZVP basis set. Values of interaction energies were corrected for basis set superposition errors using Boys-Bernardi counterpoise procedure. ${ }^{29}$ All calculations were performed using 
ORCA program. ${ }^{30}$ The analysis of the topology of intermolecular interactions in the crystal is based on vector properties of intermolecular interactions as it was described earlier. ${ }^{20,21}$ According to this approach intermolecular interaction between two molecules in the crystal may be described by vector originated in geometrical center of one molecule and directed toward geometrical center of second molecule. Length of this vector is calculated using the following equation:

$$
\mathrm{L}_{\mathrm{i}}=\left(\mathrm{R}_{\mathrm{i}} \mathrm{E}_{\mathrm{i}}\right) / 2 \mathrm{E}_{\mathrm{str}}
$$

Where $R_{i}$ is a distance between geometrical centers of interacting molecules, $E_{i}$ is the energy of interaction between these two molecules and $\mathrm{E}_{\mathrm{str}}$ is the energy of the strongest pairwise interaction in the crystal.

Application of this approach makes possible to construct the energy-vector diagram or "hedgehog" of intermolecular interactions reflecting spatial distribution of intermolecular interactions of the basic molecule located in asymmetric part of unit cell with the molecules belonging to its first coordination sphere. This diagram or hedgehog represents image of the molecule in terms of intermolecular interactions in the crystal and it may be multiplied by all symmetry operations of the crystal structure giving general picture of the topology of intermolecular interactions in the crystal. Complete list of interaction energies is included in Electronic Supporting Information.

\section{Results and Discussion}

\subsection{Computational details}

In order to evaluate the non-linear optical response of newly designed phthalimides (3a-3e), certain electric response properties such as dipole moment, polarizability and hyperpolarizability $(\beta)$ were predicted using B3LYP method with 6-31G(d,p) basis set using Gaussian 09W package. ${ }^{31}$ The predicted values of dipole moment, polarizability and hyperpolarizability and their components are depicted in tables $1-3$, respectively. The values were calculated here on the basis of finite field approach. ${ }^{32}$ This approach indicates that the molecule when present in an external electric field, the energy of the system becomes a function of the electric field. The total static dipole moment $\mu$, the mean polarizability $\alpha_{t o t}$, the mean first hyperpolarizability $\beta_{t o t}$, using the $\mathrm{x}, \mathrm{y}, \mathrm{z}$ components, they are defined as: ${ }^{15 \mathrm{a}}$

$$
\begin{gathered}
\mu_{t o t}=\left(\mu_{x}^{2}+\mu_{y}^{2}+\mu_{z}^{2}\right)^{1 / 2} \\
\alpha_{t o t}=\frac{\alpha_{x x}+\alpha_{y y}+\alpha_{z z}}{3} \\
\beta_{t o t}=\left(\beta_{x}^{2}+\beta_{y}^{2}+\beta_{z}^{2}\right)^{1 / 2}
\end{gathered}
$$

where,

$$
\begin{aligned}
& \beta_{x}=\beta_{x x x}+\beta_{x y y}+\beta_{x z z} \\
& \beta_{y}=\beta_{y y y}+\beta_{x x y}+\beta_{y z z} \\
& \beta_{z}=\beta_{z z z}+\beta_{x x z}+\beta_{y y z}
\end{aligned}
$$

Table 1. Cartesian components of dipole moment of compounds (3a-3e).

\begin{tabular}{lccccc}
\hline \multirow{2}{*}{$\begin{array}{l}\text { Dipole moment } \\
\text { coordinates }\end{array}$} & \multicolumn{5}{c}{ Dipole } \\
\cline { 2 - 6 } & $\mathbf{3 a}$ & $\mathbf{3 b}$ & $\mathbf{3 c}$ & $\mathbf{3 d}$ & $\mathbf{3 e}$ \\
\hline$\mu_{x}$ & -1.5956 & 2.6044 & 0.7028 & 3.7463 & 0.9800 \\
$\mu_{y}$ & 5.1606 & 5.0964 & 4.8983 & 5.8465 & 5.0921 \\
$\mu_{z}$ & 5.8280 & -5.5636 & -6.4375 & -4.2598 & -5.5764 \\
$\mu_{\text {tot }}$ & 7.9463 & 7.9819 & 8.1196 & 8.1463 & 7.6149 \\
\hline
\end{tabular}

Table 2. Cartesian component of molecular polarizability of compounds (3a-3e).

\begin{tabular}{lcllll}
\hline \multirow{2}{*}{$\begin{array}{l}\text { Polarizability } \\
\text { coordinates }\end{array}$} & \multicolumn{5}{c}{ Polarizability values (Debye Å) } \\
\cline { 2 - 6 } & 3a & 3b & \multicolumn{1}{c}{ 3c } & 3d & 3e \\
\hline$\alpha_{x x}$ & -224.6920 & -205.7517 & -235.1410 & -219.3559 & -187.5427 \\
$\alpha_{x y}$ & -185.0078 & -0.6701 & -5.5386 & -3.7395 & -4.1114 \\
$\alpha_{y y}$ & -220.3318 & -171.2299 & -187.7778 & -197.1030 & -166.4270 \\
$\alpha_{x z}$ & 4.8614 & -12.6485 & -11.7905 & -2.3105 & -6.2075 \\
$\alpha_{z z}$ & -8.1999 & -213.4774 & -224.4595 & -230.6263 & -206.5337 \\
$\alpha_{y z}$ & 8.7849 & -8.6755 & -8.2910 & -9.0135 & -8.1755 \\
$\alpha_{t o t}$ & -210.0105 & -590.4590 & -647.3783 & -647.0852 & -560.5034 \\
\hline
\end{tabular}


Table 3. Cartesian component of first hyperpolarizability of compounds (3a-3e).

\begin{tabular}{lccccc}
\hline \multirow{2}{*}{$\begin{array}{l}\text { Hyperpolariz-ability } \\
\text { coordinates }\end{array}$} & \multicolumn{5}{c}{ Hyperpolarizability values (Debye $\AA^{2}$ ) } \\
\cline { 2 - 5 } & $\mathbf{3 a}$ & $\mathbf{3 b}$ & $\mathbf{3 c}$ & $\mathbf{3 d}$ & $\mathbf{3 e}$ \\
\hline$\beta_{x x x}$ & -158.8705 & -26.4760 & 19.1574 & 73.3087 & -70.2612 \\
$\beta_{y y y}$ & 68.2095 & 67.4328 & 68.7058 & 73.8158 & 104.3223 \\
$\beta_{z z z}$ & 30.3760 & -60.6265 & -47.0146 & -61.1158 & -48.4157 \\
$\beta_{x y y}$ & -105.9627 & 83.5936 & 81.5071 & 43.7959 & 60.7905 \\
$\beta_{x x y}$ & 23.5674 & 23.2309 & 20.0416 & 24.4829 & -27.6092 \\
$\beta_{x x z}$ & -54.5235 & 7.7246 & 32.6780 & 67.4185 & -2.1044 \\
$\beta_{x z z}$ & -58.0501 & 16.2049 & 27.9478 & 2.3101 & 9.4649 \\
$\beta_{y z z}$ & 45.5161 & 34.1727 & 46.3879 & 47.8780 & 34.6410 \\
$\beta_{y y z}$ & 35.4047 & -26.1404 & -40.9489 & -46.5351 & -28.1415 \\
$\beta_{x y z}$ & -14.4904 & -25.8084 & -14.8762 & -15.2780 & -23.0602 \\
$\beta_{t o t}$ & 351.0409 & 164.9485 & 194.5743 & 192.9926 & 136.3356 \\
\hline
\end{tabular}

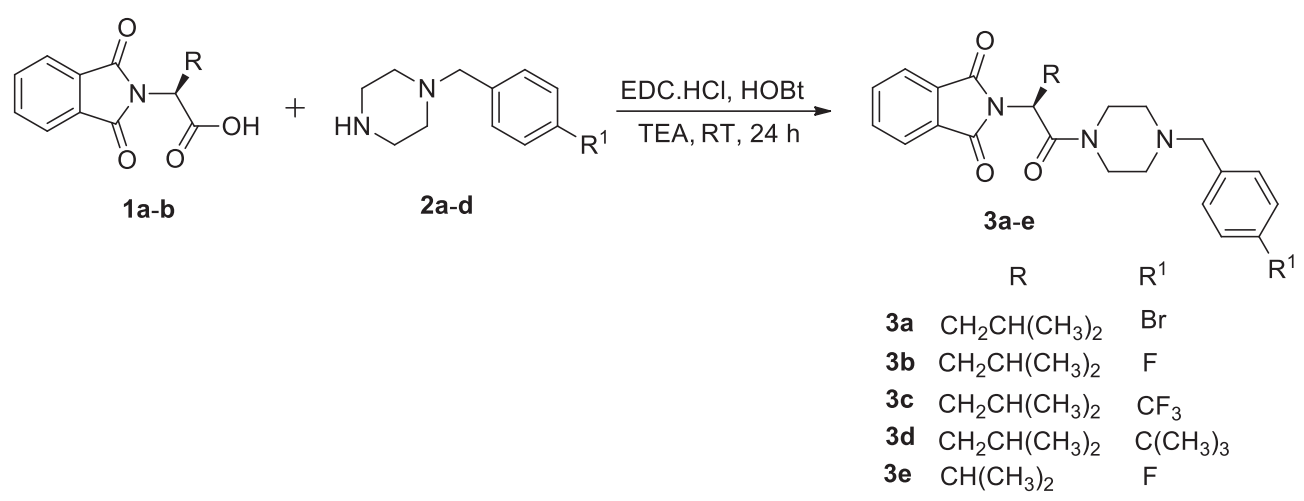

Scheme 1. Synthesis of piperazine based chiral phthalimides.

The hyperpolarizability is a third-rank tensor that can be described by a $3 \times 3 \times 3$ matrix. The 27 components of the 3D matrix can be reduced to 10 components because of the Kleinman symmetry. ${ }^{33}$ The B3LYP/6-31G $(\mathrm{d}, \mathrm{p})$ method calculated the polarizability and hyperpolarizability of the phthalimides (3a-3e) at static electric field. It is observed that the polarizabilities and first order hyperpolarisabilities of the studied molecules increase with planarity of the molecules as the substitution is increased. Overall, the results show that $\mathbf{3 a}$ would be the most reactive species among the studied molecules as well as exhibit the highest NLO responses on the basis of its calculated largest polarizabilities and first order hyperpolarizability followed by $\mathbf{3 c}, \mathbf{3 d}, \mathbf{3 b}$ and $\mathbf{3 e}$ in that order.

\subsection{Synthesis and Spectroscopic Characterization}

We have designed phthalimides possessing chirality and substituted with arylpiperazines anticipating their non-centrosymmetric structures enriched with NLO response. The synthetic strategy for new phthalimides is shown in scheme 1 .

Compounds (3a-3e) were prepared from the reaction of $\mathrm{N}$-phthaloyl-L-amino acids with corresponding piperazines in the presence of triethylamine (TEA). The reaction afforded 3a-3e as colorless solid in fair to good yield. The composition of new phthalimides was confirmed by spectroscopic techniques. Two characteristic bands at 1728 and $1638 \mathrm{~cm}^{-1}$ in the FTIR spectra of 3a-3e indicated two types of carbonyl stretching frequencies. The bands at higher frequencies are stronger and correspond to carbonyl groups present in isoindoline ring however; carbonyl group attached to the piperazine derivatives appeared at lower frequencies. In ${ }^{1} \mathrm{H}$ NMR spectrum, the signal for proton at the chiral carbon was observed as a double doublet at $\delta$ values ranging from 5.06 to $5.13 \mathrm{ppm}$. Phthalimide, $\mathbf{3 e}$ showed doublet at 4.64 having $J$ value $10.08 \mathrm{~Hz}$ and peaks for protons corresponding to the piperazine were observed as two bunches. Piperazine protons appeared as bunches of four proton each as multiplet ranging from $\delta 2.36$ to 3.67. Two distereotopic methylene protons adjacent to the chiral carbon of compounds (3a-3d) were found in the range $1.18-1.69 \mathrm{ppm}$. Peaks of aromatic protons of the isoindoline ring and piperazine linked aromatic proton were found from $\delta 6.98$ to $7.84 \mathrm{ppm}$. The peaks were assigned with the aid of $2 \mathrm{D}$ NMR spectra (see Supporting Information). The UV-Visible spectra of 3a-3e showed $\lambda_{\max }$ at $\sim 242 \mathrm{~nm}$, which indicated their 
transparency in the visible region. The UV-Visible spectra are shown in supporting information (Figure S21 in SI).

\subsection{Molecular Structure}

Results of X-ray diffraction studies indicate that all phthalimides (3a-3e) crystallized in non-centrosymmetric space groups. This confirms an existence of only one enantiomer in the crystals. All the listed phthalimides under consideration have almost the same conformation of central fragment (figure 1). Piperazine ring adopts chair conformation with deviations of the nitrogen atoms from the mean plane of the carbon atoms of cycle by $\pm 0.61-0.67 \AA$. In all molecules the amide nitrogen atom $\mathrm{N} 2$ adopts a planar geometry and the N3 atom has a pyramidal configuration. Degree of pyramidality (estimated as sum of bond angles centered at the nitrogen atom) depends on substituent and the crystal structure. This value is slightly higher for structures $\mathbf{3 a}$ and $\mathbf{3 b}$ (338.6 and $338.3^{\circ}$, respectively) indicating smaller pyramidality of the nitrogen atom as compared to structures 3c, 3d, 3e (330.0-332. $\left.8^{\circ}\right)$. Substituent at the $\mathrm{N} 3$ atom has an exo orientation in all molecules (values of the C-C-N3-C torsion angle are $\left.171.7-179.8^{\circ}\right)$. The carbonyl groups are co-planar to one of the $\mathrm{N} 2-\mathrm{C}$ bonds (the $\mathrm{C}-\mathrm{N} 2-\mathrm{C}=\mathrm{O}$ torsion angle is $\pm 3.0-10.4^{\circ}$.

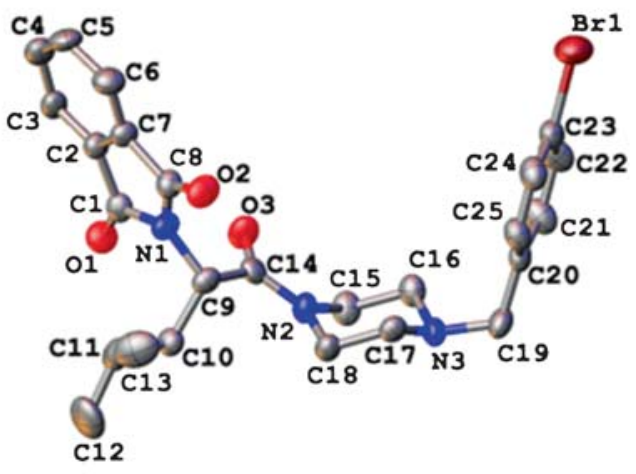

$3 a$

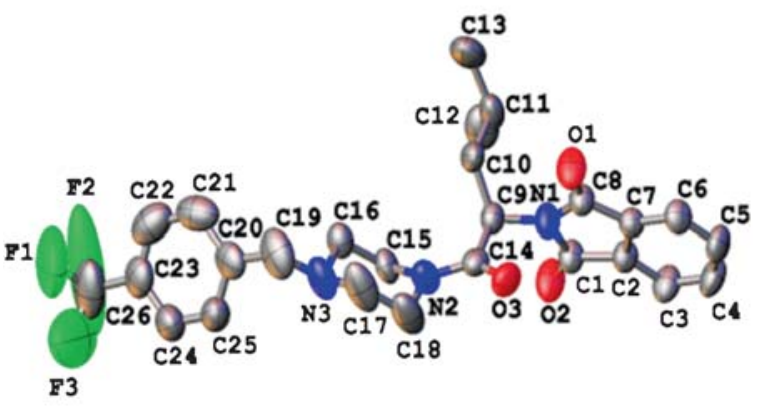

$3 c$

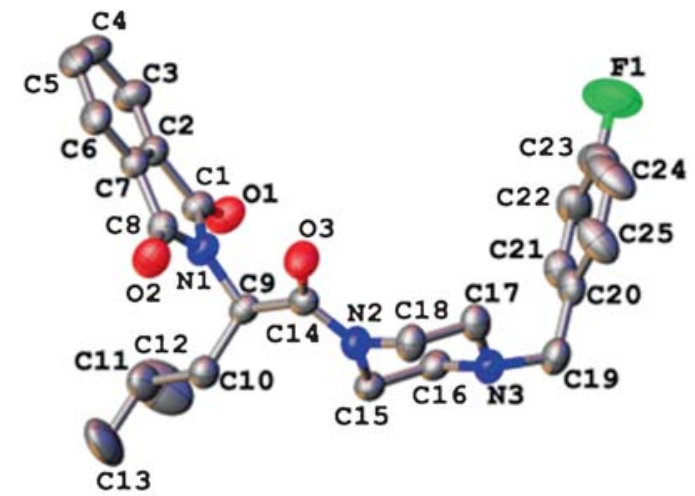

3b

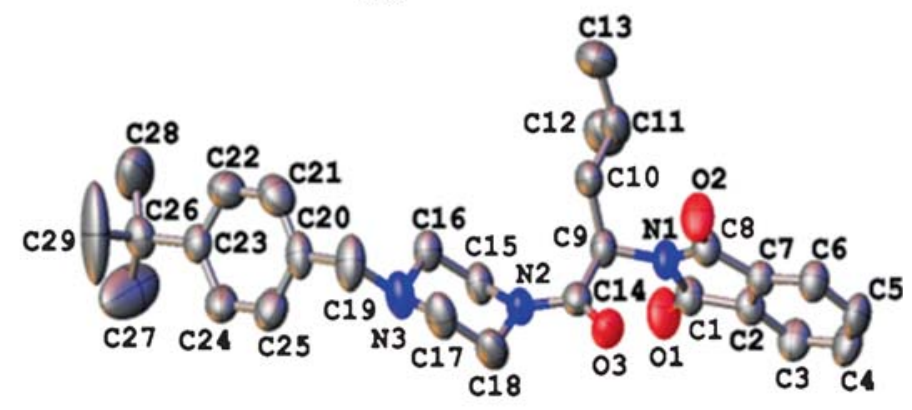

3d

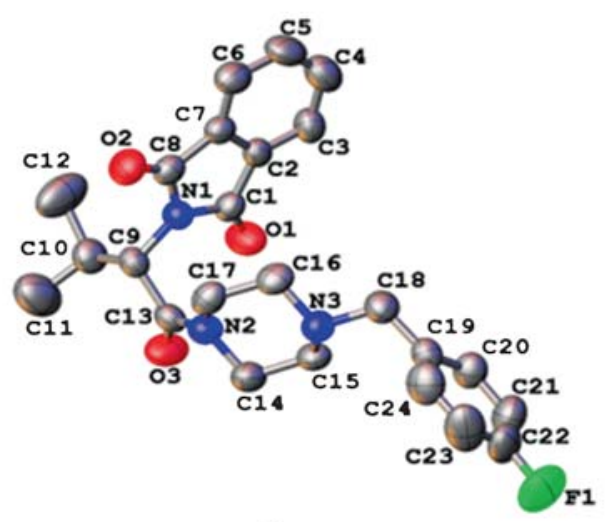

$3 e$

Figure 1. Molecular structures of phthalimides (3a-3e) according to X-ray diffraction data. Thermal ellipsoids are shown at $30 \%$ probability level. 
The main difference in conformations of molecules under consideration is caused by different orientations of aryl ring (figure 1). It is observed that two orientations of phenyl ring with respect to piperazine cycle namely, $-\mathrm{sc}$ in $\mathbf{3 a}, \mathbf{3 b}, \mathbf{3 e}$ and $+\mathrm{sc}$ in $\mathbf{3 c}, \mathbf{3 d}$ (the $\mathrm{C}(\mathrm{C} 16 / \mathrm{C} 17)-\mathrm{N} 3-\mathrm{C} 19-\mathrm{C} 20$ torsion angle is -53.7 $-66.7^{\circ}$ and $73.6-75.6^{\circ}$, respectively). The change of orientation of aryl group is accompanied by different angle of rotation of aromatic ring with respect to the N3-C19 bond (the N3-C19- $\mathrm{C}_{\mathrm{ar}}$ torsion angle is -74.3$-93.3^{\circ}$ for structures $\mathbf{3 a}, \mathbf{3 b}, \mathbf{3 e}$ and $-120.6-$ $-129.7^{\circ}$ for $\mathbf{3 c}$ and $\left.\mathbf{3 d}\right)$.

\subsection{Crystal structure}

The C-H... O bonds have several important implications in many diverse areas of structural chemistry. Taylor and Kennard in 1982 came with a conclusive evidence of existence of $\mathrm{C}-\mathrm{H}$... O hydrogen bonds in crystals. ${ }^{34}$ They showed that $\mathrm{C}-\mathrm{H}$... O contacts are electrostatic in nature and occur within certain distance $(\mathrm{C} \cdots \mathrm{O}, 3.0-4.0 \AA)$ and angle $\left(\mathrm{C}-\mathrm{H} \cdots \mathrm{O}, 90-180^{\circ}\right)$ ranges. These types of interactions are frequently used in literature as non-conventional hydrogen bonding. ${ }^{35}$ The analysis of interatomic distances in the crystals under consideration clearly indicates absence of any strong specific intermolecular interactions. Only weak $\mathrm{C}-\mathrm{H} \cdots \mathrm{O}$ and $\mathrm{C}-\mathrm{H} \cdots \pi$ interactions are observed in the crystals 3a, 3c, 3d with $\mathrm{H} \cdots \mathrm{O}$ and $\mathrm{H} \cdots \mathrm{C}(\pi)$ distances in the ranges $2.45-2.68 \AA$ and $2.82-2.85 \AA$, respectively. The crystal structure of $\mathbf{3 b}$ is stabilized by stacking interactions between parallel indole bicycles (the shortest C...C distance is $3.39 \AA$ ). The $\mathbf{3 e}$ crystal contains the very weak $\mathrm{C}-\mathrm{H} \cdots \mathrm{F}$ interaction $(\mathrm{H} \cdots \mathrm{F}$ distance is $2.62 \AA$ ) and unfavorable $\mathrm{H} \cdot \mathrm{H}$ contact where distance between the hydrogen atoms $(2.27 \AA)$ is shorter than van der Waals radii sum $(2.34 \AA)$. ${ }^{36}$

Thus, conventional approach to analysis of the crystal structures does not provide any information suitable for understanding of preferable motif of packing molecules in the crystals. Therefore, it is necessary to use another method for the analysis of supramolecular architecture of the crystals. Recently, ${ }^{20,37}$ it was suggested to use an approach based on energies and directionality of pairwise intermolecular interactions in the crystal.

In particular, this method was successfully applied for the analysis of crystals of unsubstituted fused hydrocarbons ${ }^{20}$ where other approaches for analysis of the crystal structure have failed. Results of calculations for crystals under consideration demonstrate that all the crystal structures may be divided into three groups depending on location of the most strongly bonded dimers of molecules. In the case of structures, $\mathbf{3 a}$ and $\mathbf{3 b}$, the dimers with the highest interaction energies form straight columns along $b$ crystallographic axis (table 4, figure 2). Energy of interaction of the basic molecule (BM) located in asymmetric part of unit cell with two neighbors within the same column is $-28.68 \mathrm{kcal} / \mathrm{mol}$. However, interactions between neighboring columns are strongly anisotropic (figure 2). Energy of interaction of BM with molecules belonging to one column $(-24.36 \mathrm{kcal} / \mathrm{mol})$ is comparable with energy of interaction within column. Therefore, it is possible to conclude that a basic structural motif (BSM) of the crystal is double column formed by two single columns shifted with respect to each other (figure 2). This double column may be considered also as zig-zag single column where energy of straight interactions between molecules is slightly higher than energy of diagonal interactions. Thus, crystal structure of $\mathbf{3 a}$ represents packing of double columns containing the most strongly bonded molecules. Energy of intermolecular interactions of each molecule to neighbors within double column is 4.8-7.0 times higher than the energy of interaction to

Table 4. Symmetry operation for second molecule of dimer, energy of intermolecular interactions ( $\mathrm{kcal} / \mathrm{mol})$ for five the strongest pairwise intermolecular interactions of basic molecule located in asymmetric part of unit cell and its neighbors for the structures (3a-3e).

\begin{tabular}{ccc}
\hline Entry & Symmetry operation & Energy \\
\hline 3a & $\mathrm{x}, 1+\mathrm{y}, \mathrm{z}$ & -14.34 \\
& $\mathrm{x},-1+\mathrm{y}, \mathrm{z}$ & -14.34 \\
& $1-\mathrm{x}, 1 / 2+\mathrm{y}, 1-\mathrm{z}$ & -12.18 \\
& $1-\mathrm{x},-1 / 2+\mathrm{y}, 1-\mathrm{z}$ & -12.18 \\
3b & $1-\mathrm{x}, 1 / 2+\mathrm{y},-\mathrm{z}$ & -7.60 \\
& $\mathrm{x}, 1+\mathrm{y}, \mathrm{z}$ & -14.22 \\
& $\mathrm{x}, 1+\mathrm{y}, \mathrm{z}$ & -14.22 \\
& $2-\mathrm{x}, 1 / 2+\mathrm{y}, 1-\mathrm{z}$ & -11.44 \\
3c & $2-\mathrm{x},-1 / 2+\mathrm{y}, 1-\mathrm{z}$ & -11.44 \\
& $1-\mathrm{x}, 1 / 2+\mathrm{y},-\mathrm{z}$ & -7.98 \\
& $1-\mathrm{x}, 1 / 2+\mathrm{y}, 2-\mathrm{z}$ & -11.58 \\
& $1-\mathrm{x},-1 / 2+\mathrm{y}, 2-\mathrm{z}$ & -11.58 \\
& $\mathrm{x}, 1+\mathrm{y}, \mathrm{z}$ & -8.98 \\
3d & $\mathrm{x},-1+\mathrm{y}, \mathrm{z}$ & -5.60 \\
& $2-\mathrm{x}, 1 / 2+\mathrm{y}, 2-\mathrm{z}$ & -11.48 \\
& $1-\mathrm{x}, 1 / 2+\mathrm{y},-\mathrm{z}$ & -11.48 \\
& $1-\mathrm{x},-1 / 2+\mathrm{y},-\mathrm{z}$ & -9.40 \\
& $1-\mathrm{x}, 1 / 2+\mathrm{y}, 1-\mathrm{z}$ & -9.40 \\
& $1-\mathrm{x},-1 / 2+\mathrm{y}, 1-\mathrm{z}$ & -9.08 \\
3e & $\mathrm{x},-1+\mathrm{y}, \mathrm{z}$ & -13.81 \\
& $1-\mathrm{x}, 1 / 2+\mathrm{y}, 3 / 2-\mathrm{z}$ & -13.81 \\
& $1-\mathrm{x},-1 / 2+\mathrm{y}, 3 / 2-\mathrm{z}$ & -9.33 \\
& $1 / 2+\mathrm{x}, 1 / 2-\mathrm{y}, 1-\mathrm{z}$ & -7.55 \\
\hline & $1 / 2+\mathrm{x}, 1 / 2 \mathrm{y}, 1-\mathrm{z}$ & \\
& $1+\mathrm{x}, \mathrm{y}, \mathrm{z}$ & \\
& & \\
& &
\end{tabular}




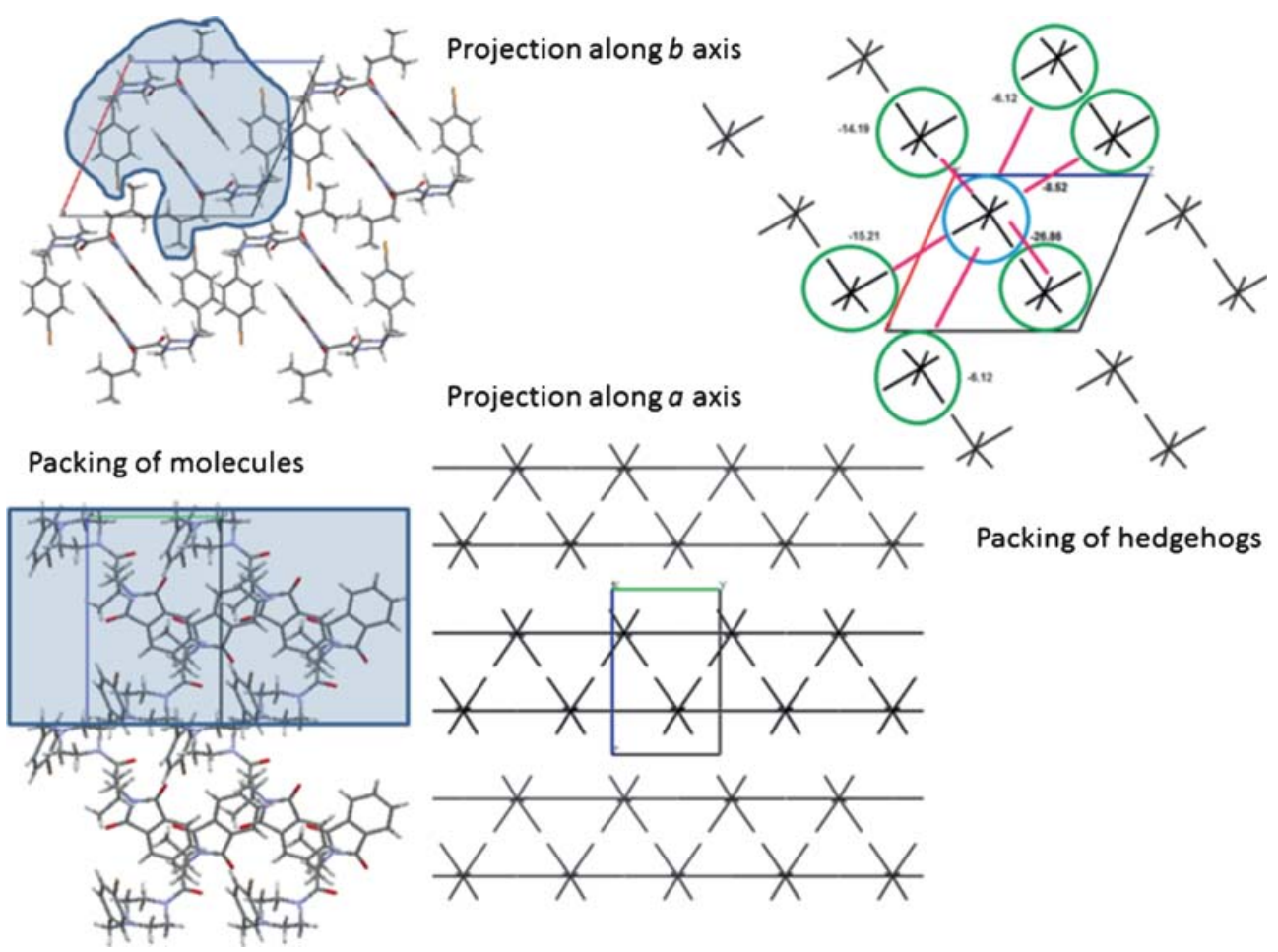

Figure 2. Packing of phthalimide 3a and hedgehogs of intermolecular interactions in the crystal double column containing the most strongly bonded molecules is highlighted.

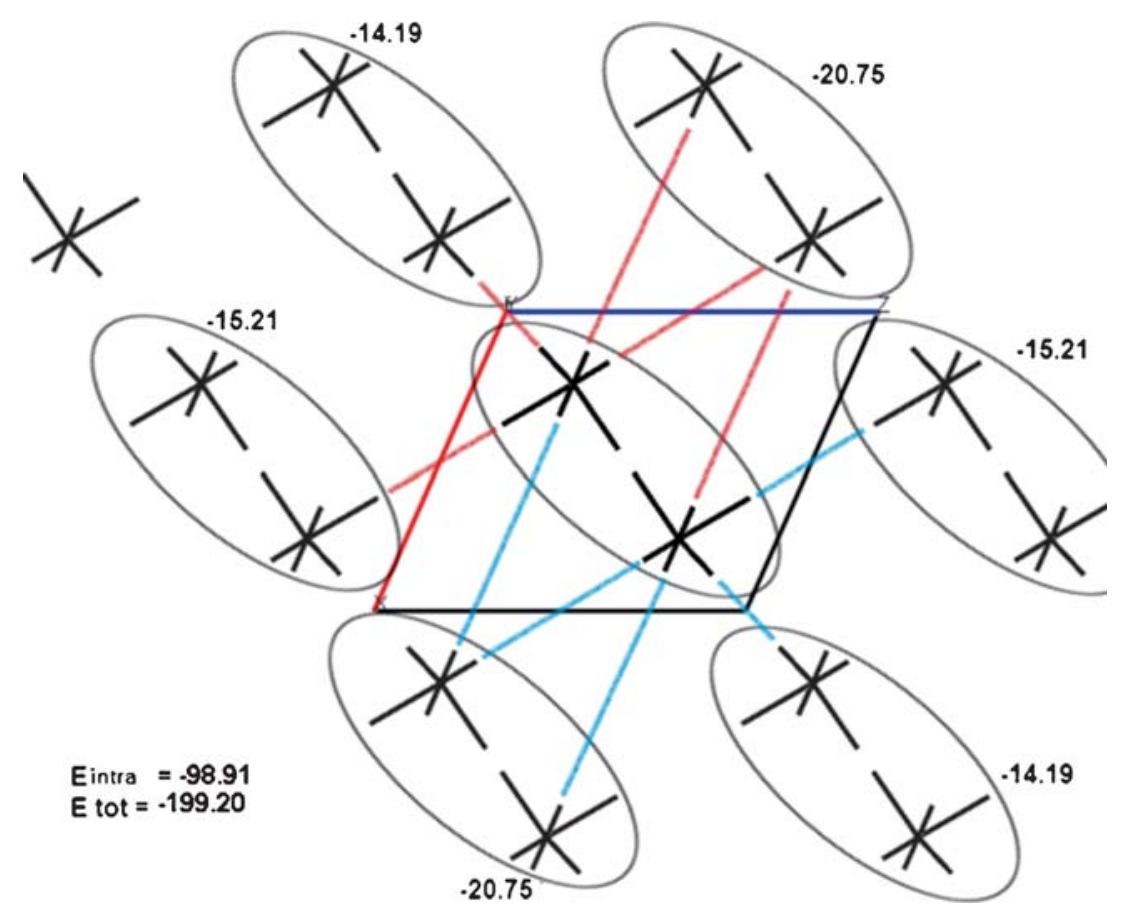

Figure 3. Energies of interactions between double columns (drawn as packing of hedgehogs of intermolecular interactions) in the crystal $\mathbf{3 a}$.

molecules belonging to neighboring columns (figure 3). It should be noted that some trend to the formation of layers of double columns, which are parallel to the (l $\left.\begin{array}{lll}0 & 0 & 1\end{array}\right)$ crystallographic plane. Energy of interactions between columns lying within $(10-1)$ crystallographic plane $(-31.92 \mathrm{kcal} / \mathrm{mol})$ is only slightly higher (by 1.2 times) than energy of interaction to molecules belonging to neighboring layer $(-25.80 \mathrm{kcal} / \mathrm{mol})$. Double 
column along $b$ crystallographic axis is a basic structural motif in the crystal of orthorhombic modification of 3e (figure 6). Energy of interactions between columns within such layer $(-41.5 \mathrm{kcal} / \mathrm{mol})$ is 1.4 times higher than energy of interaction of molecules of basic column to molecules belonging to neighboring layer $(-29.4 \mathrm{kcal} / \mathrm{mol})$.

Similar supramolecular architecture is found for the crystal $\mathbf{3 b}$ and $\mathbf{3 e}$ (figure 4). Energy of interactions within double column is 6.0-7.6 times higher than energy of interactions to neighboring six double columns. However, in contrast to structure $\mathbf{3 a}$ the crystal 3b demonstrates considerably weaker trend to layered organization of double columns (figure 5).

However, the character of interactions between the molecules becomes different. The diagonal interactions within the double column are the strongest pairwise interactions in the crystal (table 4) while energy of straight interactions between molecules is significantly smaller $(-2.22 \mathrm{kcal} / \mathrm{mol})$. Therefore, basic structural motif in this crystal should be described as zig-zag single column rather than double column (figure 6). Energy of interactions between columns within this layer $(-48.08 \mathrm{kcal} / \mathrm{mol})$ is by 1.7 times higher than energy of interaction of molecules belonging to neighboring layer $(-28.50 \mathrm{kcal} / \mathrm{mol})$.

Different supramolecular architecture is observed for the crystals $\mathbf{3 c}$ and $\mathbf{3 d}$ (figure 7). In both cases it is observed that two pairs of the most strongly bonded dimers with close enough interaction energies were observed (table 4). However, contrary to other structures, these dimers determine layers in the crystal which are parallel to $\left(\begin{array}{lll}1 & 0 & 0\end{array}\right)$ crystallographic plane. Energy of interactions of the basic molecules to neighbors within layer is by 3.1-3.7 times higher than energy of interaction of BM to molecules belonging to the neighboring layer. It should be noted that the dimers with the energies of interactions also form zig-zag columns along $b$ crystallographic axis in structures $\mathbf{3 c}$ and $\mathbf{3 d}$ similar to 3e. However, these columns are strongly bonded with neighbors within layer. It should be noted that molecules $\mathbf{3 c}$ and $\mathbf{3 d}$ have slightly bigger substituents in the aryl ring. Therefore, it is possible to suppose that increase in size of this substituent leads to the transformation of columnar structure of crystal to layered.

\subsection{SHG Measurements}

In order to validate our computational results, the crystalline forms of 3a-3e were evaluated for SHG response by a modified Kurtz-Perry powder method. ${ }^{38}$ The observed SHG response for all the phthalimides (3a$\mathbf{3 e}$ ) is shown in chart 2 . Phthalimides $\mathbf{3 b}$ and $\mathbf{3 d}$ crystallised in monoclinic system ( $P 2_{1}$ space group) exhibited higher SHG values, 16.0 and $16.4 \mathrm{mV}$, respectively. However, compound $\mathbf{3 e}$ crystallized in orthorhombic

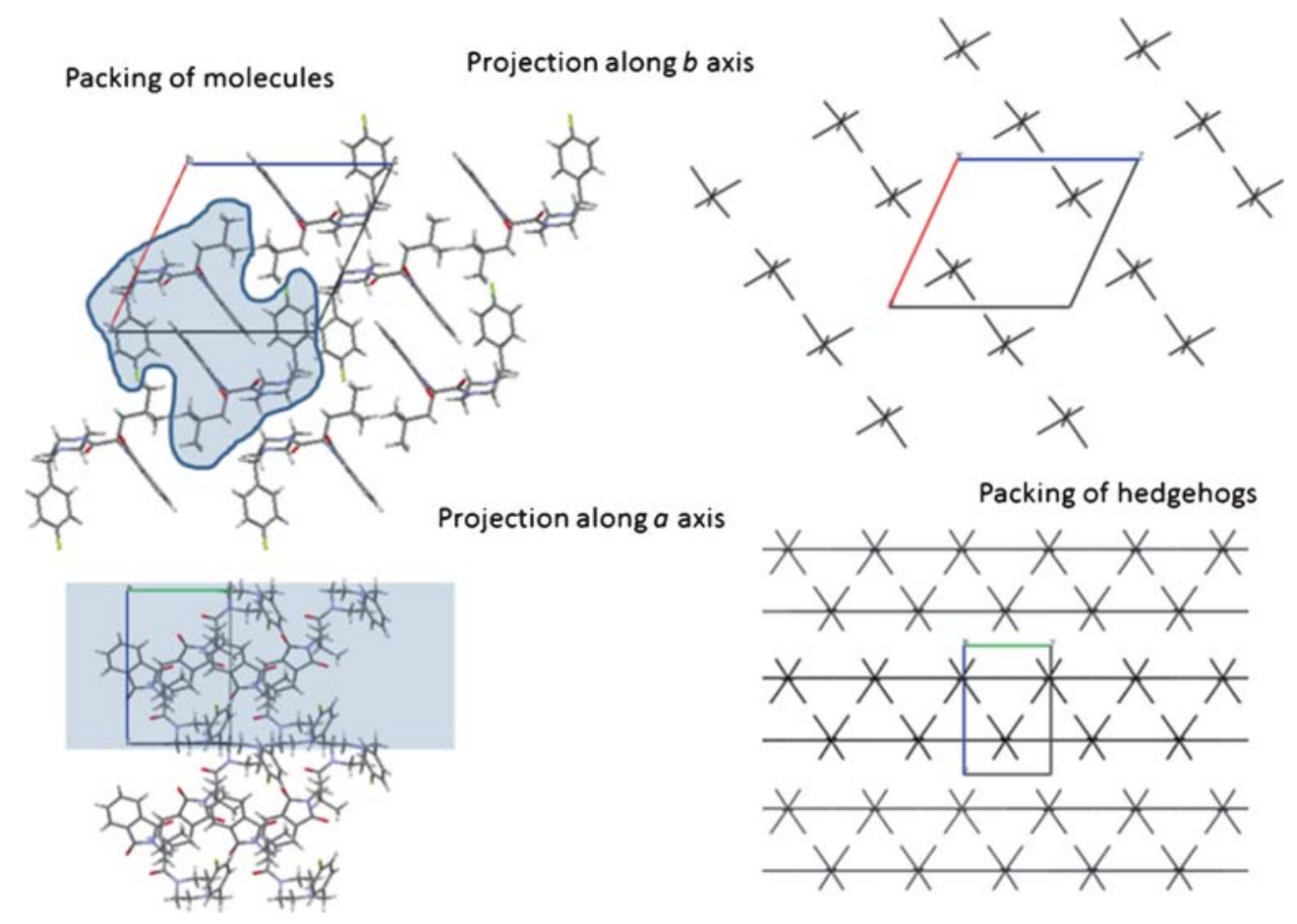

Figure 4. Packing of molecules and hedgehogs of intermolecular interactions in the crystal 3b. Double column containing the most strongly bonded molecules is highlighted. 


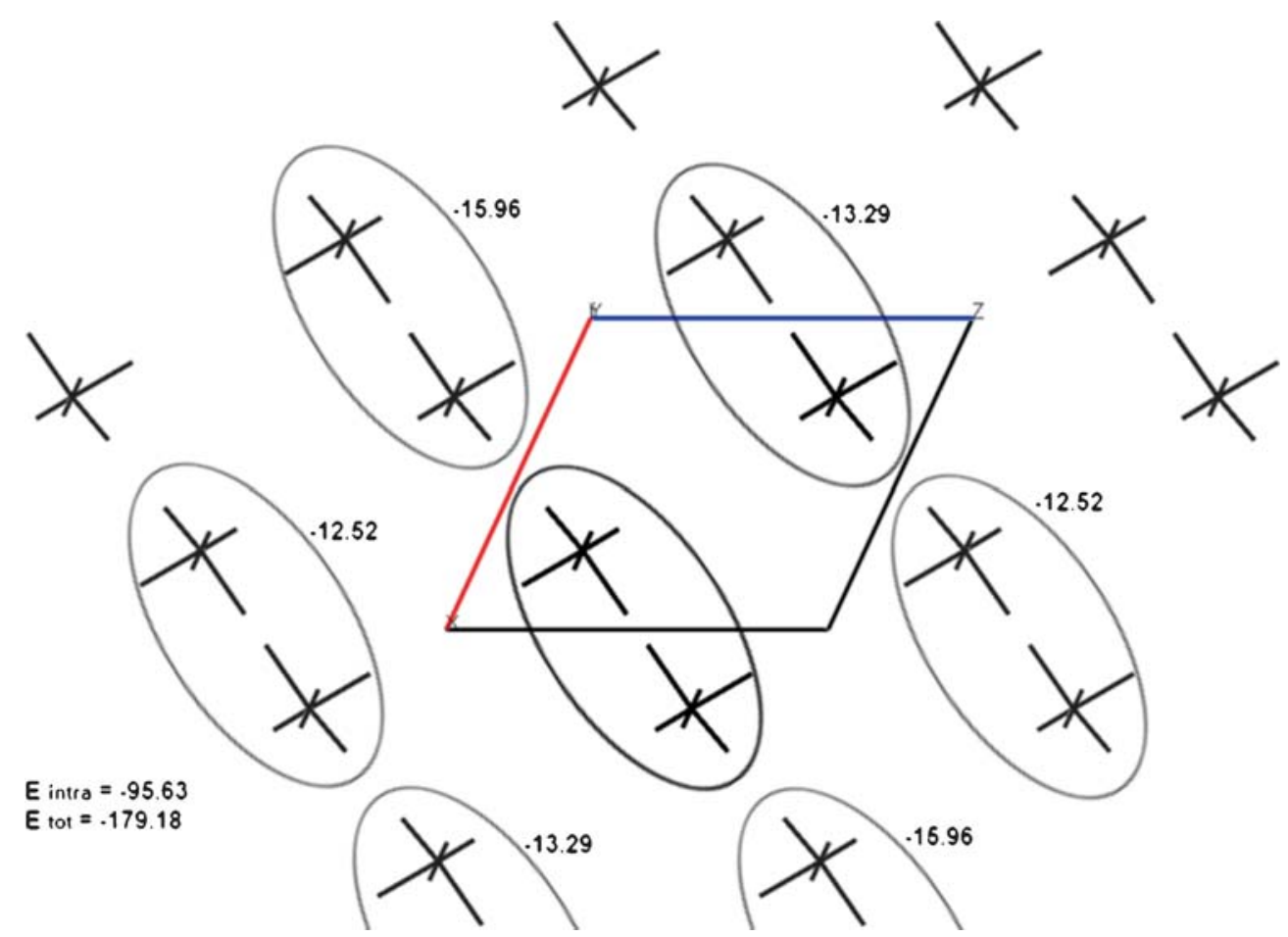

Figure 5. Energies of interactions between double columns (drawn as packing of hedgehogs of intermolecular interactions) in the crystal $\mathbf{3 b}$.

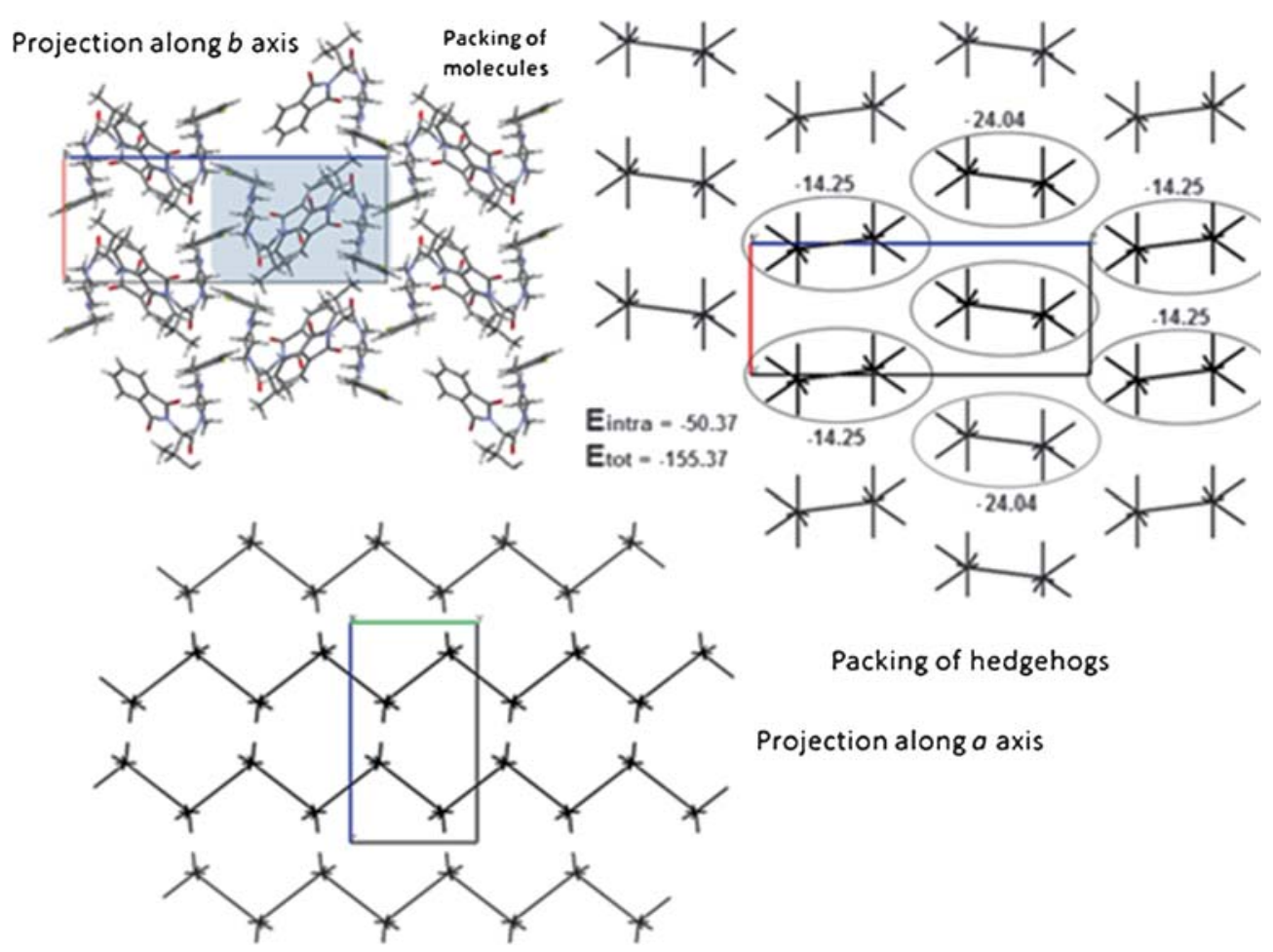

Figure 6. Packing of molecules and hedgehogs of intermolecular interactions in the crystal 3e. Zig-zag column containing the most strongly bonded molecules is highlighted.

system $\left(P 2_{1} 2_{1} 2_{1}\right.$ space group) showed lower SHG value of $14.0 \mathrm{mV}$. Phthalimides 3c possessing trifluoro substituent showed lowest SHG value $(13.2 \mathrm{mV})$. A significant value of SHG of $16.4 \mathrm{mV}$ was recorded for 3d, which is higher than the reference, $\operatorname{KDP}(15.2 \mathrm{mV})$. The high response of SHG may be partly attributed to 

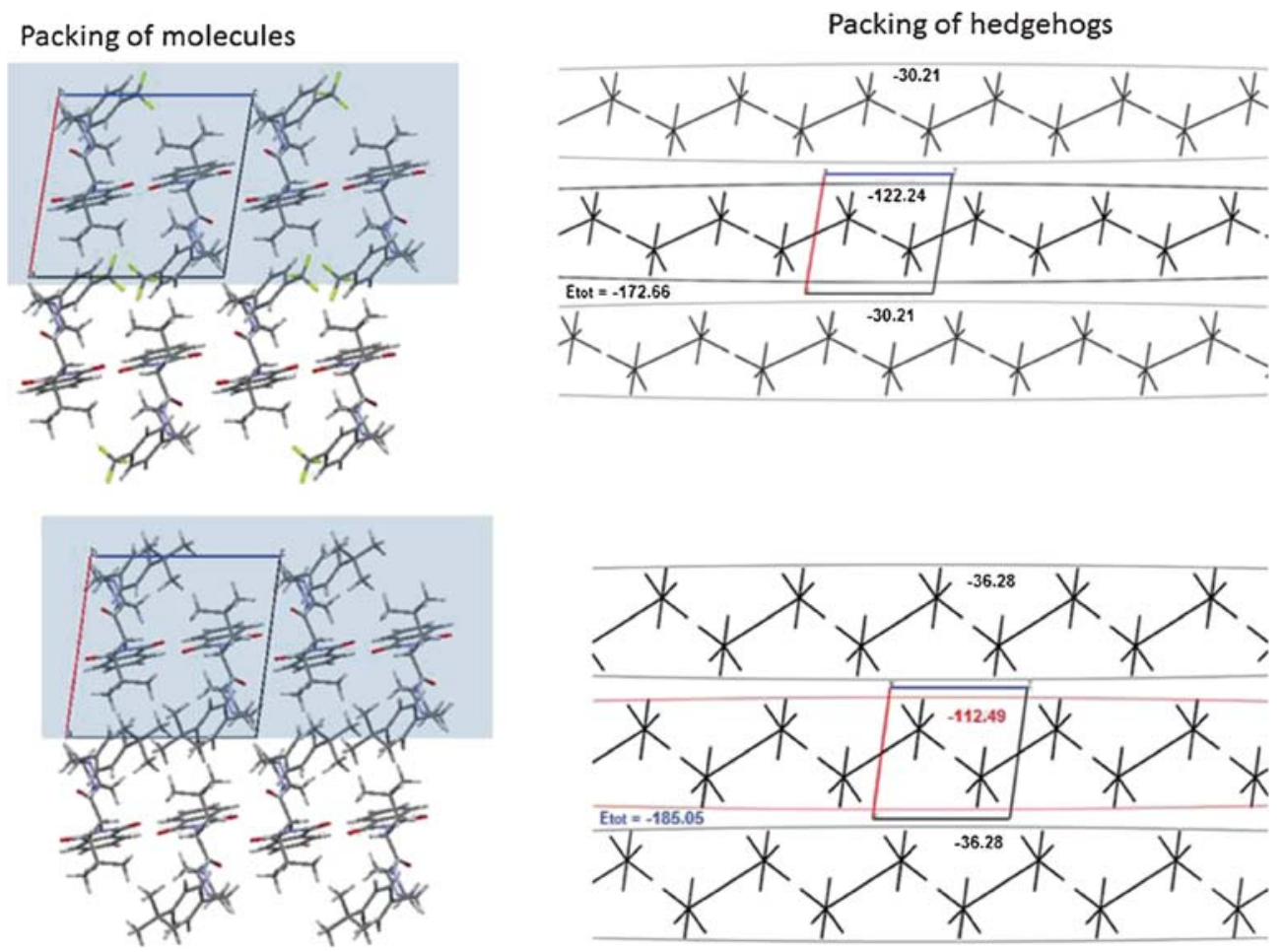

Figure 7. Packing of molecules and hedgehogs of intermolecular interactions in the crystals of $\mathbf{3 c}$ (top) and 3d (bottom). Layers of strongly bonded molecules are highlighted.<smiles>CC(C)C[C@H](C(=O)N1CCN(Cc2ccc(Br)cc2)CC1)N1C(=O)c2ccccc2C1=O</smiles>

SHG $14.9 \mathrm{mV}$<smiles>CC(C)C[C@H](C(=O)N1CCN(Cc2ccc(F)cc2)CC1)N1C(=O)c2ccccc2C1=O</smiles>

monoclinic system $P 21$ SHG $16.0 \mathrm{mV}$<smiles>CC(C)C[C@H](C(=O)N1CCN(Cc2ccc(C(F)(F)F)cc2)CC1)N1C(=O)c2ccccc2C1=O</smiles><smiles>CC(C)C[C@H](C(=O)N1CCN(Cc2ccc(C(C)(C)C)cc2)CC1)N1C(=O)c2ccccc2C1=O</smiles><smiles>CC(C)C(C(=O)N1CCN(Cc2ccc(F)cc2)CC1)N1C(=O)c2ccccc2C1=O</smiles>

orthorhombic system

$P 2{ }_{1}{ }_{1}{ }_{2}$

SHG $14.0 \mathrm{mV}$

Chart 2. Novel piperazine based phthalimides possessing significant SHG response.

the high energy interactions forming zig-zag columns in the solid state of $\mathbf{3 d}$. Secondly, the bulky tert-butyl substituent at the para position of arylpiperazine in phthalimide 3d generates push-pull character, which ultimately leads to the enhanced SHG response.

\subsection{Thermogravimetric and differential thermal analysis (TGA-DTA)}

In order to determine the thermal stability, thermogravimetric analysis (TGA) of $\mathbf{3 a - 3 e}$ was conducted 
and the plots are given in the supporting information (Figures S16-20). The thermal analysis of all the compounds was carried out using Perkin Elmer Diamond instrument. The heating was under nitrogen atmosphere at $10^{\circ} \mathrm{C} / \mathrm{min}$. The onset of the decomposition of compounds lies in between $194^{\circ} \mathrm{C}$ (for compound $\mathbf{3 b}$ ) and $254^{\circ} \mathrm{C}$ (for compound 3c). The DTA curve shows a major endothermic peak, which corresponds to the melting point of the compounds. At higher temperatures, decomposition process continues up to $600^{\circ} \mathrm{C}$ with the removal of almost the entire compound as gaseous products. The sharpness of the endothermic peak shows good degree of crystallinity of the compounds. Out of these observations we can conclude that phthalimides are fairly stable.

\section{Conclusions}

In conclusion, we have introduced novel chiral phthalimides possessing aryl piperazines as a new class of non-centrosymmetric organic crystals. The incorporation of chiral amino acid linker may be attributed to the generation of non-centrosymmetric structure in the solid state. It was noticed that the nature of terminal arylpiperazines is crucial in the context of SHG response. The significant SHG response of phthalimide $\mathbf{3 d}$ may be attributed to the substitution at para position i.e., electron donating nature of $t$-butyl group. Chiral phthalimides have been investigated as promising candidates for helical supramolecular framework stabilized by hydrogen bonding as revealed by the energy of intermolecular interaction. The current study advocates this novel class of chiral phthalimides as a strong contender for future technology applications.

\section{Supplementary Information}

All additional information relating to characterization of the compounds such as NMR spectras (Figures S1-S15), TGA-DTA plots (Figures S16-S20), UV-Vis spectra (Figure S21), supramolecular architecture of crystals presented as packing of molecules and hedgehogs of intermolecular interactions (Figures S23S27), Crystallographic data (Table S1), Geometrical parameters of intermolecular interactions in crystals (Table S2) and Numbering of dimers, symmetry operation of second molecule of dimer and energy of intermolecular interactions in dimers formed by the basic molecule in the crystals (Tables S3-S7) are given in the supporting information available at www.ias.ac.in/ chemsci.

\section{Acknowledgements}

BR is grateful to the Department of Science and Technology, Ministry of Science and Technology, India for financial support (SR/FT/CS-108/2010). Scientific collaboration was possible due to India-Ukraine Bilateral Scientific Cooperation program supported by Department of Science and Technology, Ministry of Science \& Technology, India and The Ukrainian State Agency for Science, Innovation, and Informatization (0114U003690). We are thankful to Dr. Svetlana V. Shishkina for her valuable corrections. AKS and VB are thankful to CSIR, India for providing Senior Research Fellowship.

\section{References}

1. (a) Badan J, Hierle R, Perigaud A and Zyss J 1993 In American Chemical Society Symposium Series 233 (American Chemical Society: Washington, DC); (b) Prasad P N and Williams D J 1991 In Introduction to non-linear optical effects in organic molecules and polymers (Wiley: New York); (c) Brédas J L and Meyers F 1995 Nature 375 362; (d) Yu H, Wu H, Pan S, Yang Z, Hou X, Su X, Jing Q, Poeppelmeier K R and Rondinelli J M 2014 J. Am. Chem. Soc. 136 1264; (e) Stokes G Y and Conboy J C 2014 J. Am. Chem. Soc. 136 1409; (f) Eaton D F 1991 Science 253 28; (g) Lambert C, Nöll G, Schmälzlin E, Meerholz K and Bräuchle C 1998 Chem. Eur. J. 4 2129; (h) Wojciechowski A, Ozga K, Reshak AH, Miedzinski R, Kityk I V, Berdowski J and Tylczyński Z 2010 Mater. Lett. 64 1957; (i) Ozga K, Reshak A H, Berdowski J, Tylczyński Z, Wojciechowski A, Ślęzak A and Kityk I V 2011 Mater. Lett. 65 1734

2. (a) Zyss J and Chemla D S 1987 In Nonlinear Optical properties of Organic Molecules and Crystals, Vol. 1 (Academic Press: New York); (b) Bosshard C, Sutter K, Prgtre P, Hulliger J, Florsheimer M, Kaatz P and Gunter P 1995 In Organic Nonlinear Optical Materials (Gordon and Breach Science Publishers: Amsterdam); (c) Adur J, Carvalho H F, Cesar C L and Casco V H 2014 Cancer Inform. 13 67; (d) Diederichs C, Tignon J, Dasbach G, Ciuti C, Lemaitre A, Bloch J, Roussignol P and Delalande C 2006 Nature 440 904; (e) Samoc M, Gauthier N, Cifuentes M P, Paul F, Lapinte C and Humphrey M G 2006 Angew. Chem. Int. Ed. 45 7376; (f) Davydyuk G E, Khyzhun O Y, Reshak A H, Kamarudin H, Myronchuk G L, Danylchuk S P, Fedorchuk A O, Piskach L V, Mozolyuk M Y and Parasyuk O V 2013 Phys. Chem. Chem. Phys. 15 6965

3. (a) Gunter P 2000 In Nonlinear Optical Effects and Materials Springer Series in Optical Sciences Vol. 72 (Springer: Berlin); (b) Champagne B, Plaquet A, Pozzo $\mathrm{J}$ L, Rodriguez V and Castet F $2012 \mathrm{~J}$. Am. Chem. Soc. 134 8101; (c) Deussen H-J, Boutton C, Thorup N, Geisler T, Hendrickx E, Bechgaard K, Persoons A Â and 
Bjùrnholm T 1998 Chem. Eur. J. 4 240; (d) Coluccini C, Sharma A K, Caricato M, Sironi A, Cariati E, Righetto S, Tordin E, Botta C, Forni A and Pasini D 2013 Phys. Chem. Chem. Phys. 151666

4. Malfant I, Cordente N, Lacroix P G and Lepetit C 1998 Chem. Mater. 104079

5. (a) Zhao S, Gong P, Bai L, Xu X, Zhang S, Sun Z, Lin Z, Hong M, Chen C and Luo J 2014 Nat. Commun. 5 4019; (b) Compain J D, Mialane P, Dolbecq A, Marrot J, Proust A, Nakatani K, Yu P and Secheresse F 2009 Inorg. Chem. 48 6222; (c) Lacroix PG 1995 Chem. Mater. 7 1293; (d) Hsiue G-H, Lee R-H and Jeng R-J 1997 Chem. Mater. 9 883; (e) Lebeau B, Brasselet S, Zyss J and Sanchez C 1997 Chem. Mater. 9 1012; (f) Lacroix P G 2001 Chem. Mater. 13 3495; (g) Sun H, Tian X, Wang J, Zhang J, Yuan Y and Sun Z R 2011 J. Phys. Chem. A 11514495

6. (a) Kanis D R, Ratner M A and Marks T J 1994 Chem. Rev. 94 195; (b) Torre G, Vázquez P, López F A and Torres T 2004 Chem. Rev. 104 3723; (c) Ostroverkhova O and Moerner W E 2004 Chem. Rev. 1043267

7. Patil P S, Dharmaprakash S M, Ramakrishna K, Fun HK, Sai R, Kumar S and Rao D N 2007 J. Cryst. Growth 303520

8. (a) Russell V A, Etter M C and Ward M D 1994 Chem. Mater. 6 1206; (b) Radhakrishnan T P 2008 Acc. Chem. Res. 41367

9. Zhao B, Lu W-Q, Zhou Z-H and Wub Y 2000 J. Mater. Chem. 101513

10. Oudar J and Hieple R 1977 J. Appl. Phys. 482699

11. (a) Wang Y and Eaton D F 1985 Chem. Phys. Lett. 120 441; (b) Barron L D 1982 In Molecular Light Scattering and Optical Activity (Cambridge Univ. Press: Cambridge)

12. (a) Moerner W E and Silence S M 1994 Chem. Rev. 94 127; (b) Burland D M, Miller R D and Walsh C A 1994 Chem. Rev. 94 31; (c) Marks T J and Ratner M A 1995 Angew. Chem. Int. Ed. Engl. 34155

13. (a) Bossi D E and Ade R W 1992 Laser Focus World 28 135; (b) Higgins T V 1992 Laser Focus World 28125

14. Prakash M J and Radhakrishnan T P 2005 Cryst. Growth. Des. 51831

15. (a) Singh A K, Kishan R, Vijayan N, Balachandran V, Singh T, Tiwari H K, Singh B K and Rathi B 2013 RSC Adv. 3 14750; (b) Singh A K, Kishan R, Bahadur V, Vijayan N, Balachandran V, Tiwari H K, Singh B K and Rathi B 2014 J. Phy. Org. Chem. 27490
16. Schwarzer A and Weber E 2008 Cryst. Growth Des. 8 2862

17. (a) Pal D, Suhnel J and Weiss M S 2002 Angew. Chem. Int. Ed. 41 4663; (b) Larsen P L, Parolin T J, Powell D R, Hedrich M P and Borovik A S 2003 Angew. Chem. Int. Ed. $\mathbf{4 2} 85$

18. Barooah N, Sarma R J and Baruah J B 2003 Cryst. Growth Des. 3639

19. Mallakpour S and Rafiee Z 2008 Polym. Adv. Technol. 191474

20. Shishkin O V, Dyakonenko V V and Maleev A V 2012 Cryst. Eng. Comm. 141795

21. Yufit D S, Zubatyuk R, Shishkin O V and Howard J A K 2012 Cryst. Eng. Comm. 148222

22. Macrae C F, Bruno I J, Chisholm J A, Edgington P R, McCabe P, Pidcock E, Rodriguez-Monge L, Taylor R and van Streek J 2008 de and Wood P A J. Appl. Cryst. 41466

23. Hohenberg P and Kohn W 1964 Phys. Rev. 136B 864

24. Parr R G and Yang W 1989 In Density Functional Theory of Atoms and Molecules (Oxford University Press: New York)

25. Becke A D 1988 Phys. Rev. A 383098

26. Becke A D 1993 J. Chem. Phys. 985648

27. Lee C, Yang W and Parr R G 1988 Phys. Rev. B 37785

28. Grimme S, Antony J, Ehrlich S and Krieg H $2010 \mathrm{~J}$. Chem. Phys. 132154104

29. Boys S F and Bernardi F 1970 Mol. Phys. 19553

30. Neese F 2010 ORCA 280 (Universitaet Bonn: Germany)

31. Frisch M J, Trucks G W, Schlegel H B et al. 2009 GAUSSIAN 09: Revision A. 02 (Gaussian. Inc.:Wallingford, CT)

32. Kudin K N and Scuseria G E 2000 J. Chem. Phys. 113 7779

33. Kleinman D A 1962 Phys. Rev. 1261977

34. Taylor R and Kennard O 1982 J. Am. Chem. Soc. 104 5063

35. (a) Desiraju G R 1991 Acc. Chem. Res. 24 290; (b) Desiraju G R 1996 Acc. Chem. Res. 29 441; (c) Steiner T 1996 Crystallogr. Rev. 6 1; (d) Steiner T 1997 Chem. Commun. 727

36. Zefirov Yu V 1997 Kristallografiya 42936 (in Russian)

37. Dyakonenko V V, Maleev A V, Zbruyev A I, Chebanov V A, Desenko S M and Shishkin O V 2010 Cryst. Eng. Comm. 121816

38. Kurtz S K and Perry T T 1968 J. Appl. Phys. 393798 